\title{
Total utilization of lignin and carbohydrates in Eucalyptus grandis: an integrated biorefinery strategy towards phenolics, levulinic acid, and furfural
}

\author{
Xue Chen ${ }^{1}$, Kaili Zhang ${ }^{1}$, Ling-Ping Xiao ${ }^{2^{*}}$, Run-Cang Sun ${ }^{2}$ and Guoyong Song ${ }^{1^{*}}$ (D)
}

\begin{abstract}
Background: Lignocellulosic biomass, which is composed of cellulose, hemicellulose and lignin, represents the most abundant renewable carbon source with significant potential for the production of sustainable chemicals and fuels. Current biorefineries focus on cellulose and hemicellulose valorization, whereas lignin is treated as a waste product and is burned to supply energy to the biorefineries. The depolymerization of lignin into well-defined mono-aromatic chemicals suitable for downstream processing is recognized increasingly as an important starting point for lignin valorization. In this study, conversion of all three components of Eucalyptus grandis into the corresponding monomeric chemicals was investigated using solid and acidic catalyst in sequence.

Results: Lignin was depolymerized into well-defined monomeric phenols in the first step using a Pd/C catalyst. The maximum phenolic monomers yield of $49.8 \mathrm{wt} \%$ was achieved at $240{ }^{\circ} \mathrm{C}$ for $4 \mathrm{~h}$ under $30 \mathrm{~atm} \mathrm{H}_{2}$. In the monomers, 4-propanol guaiacol (12.9 wt\%) and 4-propanol syringol (31.9 wt\%) were identified as the two major phenolic products with $90 \%$ selectivity. High retention of cellulose and hemicellulose pulp was also obtained, which was treated with $\mathrm{FeCl}_{3}$ catalyst to attain 5-hydroxymethylfurfural, levulinic acid and furfural simultaneously. The optimal reaction condition for the co-conversion of hemicellulose and cellulose was established as $190^{\circ} \mathrm{C}$ and $100 \mathrm{~min}$, from which furfural and levulinic acid were obtained in $55.9 \%$ and $73.6 \%$ yields, respectively. Ultimately, $54 \%$ of Eucalyptus sawdust can be converted into well-defined chemicals under such an integrated biorefinery method.
\end{abstract}

Conclusions: A two-step process (reductive catalytic fractionation followed by $\mathrm{FeCl}_{3}$ catalysis) allows the fractionation of all the three biopolymers (cellulose, hemicellulose, and lignin) in Eucalyptus biomass, which provides a promising strategy to make high-value chemicals from sustainable biomass.

Keywords: Eucalyptus, Reductive catalytic fractionation, Phenolic monomers, Platform chemicals

\footnotetext{
*Correspondence: Ipxiao@dlpu.edu.cn; songg@bjfu.edu.cn

1 Beijing Key Laboratory of Lignocellulosic Chemistry, Beijing Forestry

University, Beijing 100083, China

${ }^{2}$ Center for Lignocellulose Science and Engineering, Liaoning Key

Laboratory of Pulp and Paper Engineering, School of Light Industry

and Chemical Engineering, Dalian Polytechnic University, Dalian 116034,

China
}

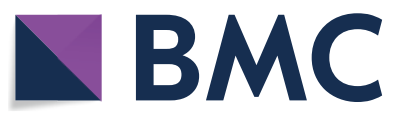

(c) The Author(s) 2020. This article is licensed under a Creative Commons Attribution 4.0 International License, which permits use, sharing, adaptation, distribution and reproduction in any medium or format, as long as you give appropriate credit to the original author(s) and the source, provide a link to the Creative Commons licence, and indicate if changes were made. The images or other third party material in this article are included in the article's Creative Commons licence, unless indicated otherwise in a credit line to the material. If material is not included in the article's Creative Commons licence and your intended use is not permitted by statutory regulation or exceeds the permitted use, you will need to obtain permission directly from the copyright holder. To view a copy of this licence, visit http://creative commons.org/licenses/by/4.0/. The Creative Commons Public Domain Dedication waiver (http://creativecommons.org/publicdomain/ zero/1.0/) applies to the data made available in this article, unless otherwise stated in a credit line to the data. 


\section{Background}

Lignocellulosic biomass, which is composed of lignin, cellulose, and hemicellulose, represents the prevalent sustainable hydrocarbon resource for impactful conversion into our future chemicals and fuels [1-3]. Achieving high overall product yields from all three biopolymers in an integrated process has great potential to promote future biorefinery technologies. Current lignocellulosic biorefinery predominantly gears to carbohydrate (cellulose and hemicellulose) valorization [4-6]. Typical biorefinery procedures included a pretreatment process, i.e., Kraft, sulphite and organosolv processes, by which lignin component was initially extracted and separated [7-9]. Alternatively, direct acid-treatment of biomass sawdust was also established, wherein (hemi)cellulose components were preferentially converted into platform compounds, such as furfural, 5-hydroxymethylfurfural (5-HMF), levulinic acid (LA), and so on [10-14]. Of note, these procedures negatively affect the depolymerization of lignin into monomers because stable $\mathrm{C}-\mathrm{C}$ linkages would be formed irreversibly through depolymerization-recondensation of lignin $[15,16]$. As a consequence, the upgrading of lignin to useful products has not been realized in a successful version.

The depolymerization of lignin into well-defined mono-aromatic chemicals suitable for downstream processing would be an important starting point for the valorization of lignin as well as the promotion of the economics of biorefineries [17, 18]. Recently, the direct reductive catalytic fractionation (RCF) of lignocellulosic biomass was emerged as a new protocol for biomass fractionation and lignin depolymerization [15, 19]. Such processes usually employed a heterogeneous catalyst based on ruthenium $[20,21]$, palladium [2228], nickel [29-31], copper [32], and molybdenum metals [33-35]. During RCF, protolignin in lignocellulose matrix was firstly depolymerized into phenolic monomers through the cleavage of $\mathrm{C}-\mathrm{O}$ bonds in $\beta-O-4$ linkages $[8,35]$. The selectivity-control of monophenols bearing different endchains at para position, such as propyl [22, 36], propenyl [37], propanol [38], ethyl and allyl ether [34, 35], has been realized by the choice of catalysts and/or additives [39]. The RCF process also left a solid fraction as a pulp containing cellulose and hemicellulose components with high retentions, which could be readily retrieved by filtration process. This provides an ideal carbohydrate feedstock for subsequent upgrading because the biomass recalcitrance has been broken down. For most cases, the cellulose component could be readily enzymatically hydrolyzed to glucose after RCF process [23, 40, 41]. Hydrolytic hydrogenation of (hemi)cellulose residues into pentitols from hemicellulose and hexitols from cellulose has already been studied by using $\mathrm{Ru} / \mathrm{C}$ catalyst [20].

The hydrolysis of either hemicellulose into furfural, or cellulose into 5-HMF (and subsequent LA) has been widely reported [42-44], while integrated catalytic conversion of this two biopolymers to co-produce platform compounds is still limited, because of the significant difference in their chemical properties [45]. Dumesic and coworkers reported that the hemicellulose and cellulose components in corn stover sawdust can be converted into levulinic acid and furfural simultaneously with $\mathrm{H}_{2} \mathrm{SO}_{4}$ catalyst in $\gamma$-valerolactone (GVL) [11]. Wyman et al. found that metal halides could serve as an efficient catalyst for the production of furfural, 5-HMF and LA with high yields from lignocellulosic biomass [46]. A recent work by Abu-Omar and coworkers suggested that the solid hemi(cellulose) residue, which generated from $\mathrm{Ni}$ catalyzed RCF of Miscanthus, could be converted into LA and furfural with a Lewis acid catalyst under microwave heating [47].

Eucalyptus is considered as one of the fastest-growing sources of fiber, which is widely applied to artificial board, pulping, and paper-making industries owing to its wide adaptability and high photosynthesis. We recent reported the RCF of hardwood, softwood and herbaceous plants with Mo [33-35], Ni [30,31] and Pd [23] catalysts. These results encourage us to continually explore the transformation of all three biopolymers into monomeric chemicals based on RCF process. In this paper, we used $\mathrm{Pd} / \mathrm{C}$ as a catalyst to treat Eucalyptus sawdust, thus resulting in 4-propanol guaiacol/syringol with high yield from depolymerization of lignin component. High retention of cellulose and hemicellulose pulp was also obtained, which on the treatment with cheaply available $\mathrm{FeCl}_{3}$ catalyst led to the formation of 5-HMF, LA and furfural simultaneously. Finally, all the three biopolymers (cellulose, hemicellulose, and lignin) in Eucalyptus biomass were efficiently transformed into well-defined chemicals and fuels via an integrated protocol involving RCF and acidic catalysis processes (Fig. 1).

\section{Results and discussion}

\section{Monomeric phenols from RCF of Eucalyptus}

A series of heterogeneous metal catalysts have been employed in direct treatment of biomass sawdust. In view of the combination of high yield of phenolic monomers and high retention of carbohydrate pulp, $\mathrm{Pd} / \mathrm{C}$ was chosen as the catalyst [23]. The RCF reaction of Eucalyptus sawdust (40-60 mesh) was carried out in a batch reactor with $\mathrm{Pd} / \mathrm{C}$ (10 wt\% dosage) under $\mathrm{H}_{2}(30 \mathrm{~atm})$ in methanol. A range of temperatures were screened for $4 \mathrm{~h}$. The lignin monomer yields, the average molecular weight $\left(M_{\mathrm{w}}\right)$ of the lignin oil and the retention of the sugars 
are summarized in Table 1 (Additional file 1: Table S2). The soluble fraction contained monomeric, dimeric and oligomeric phenols derived from depolymerization of lignin, as well as polyols derived from partial hydrolysis of (hemi)cellulose. The identification and quantification of lignin monomers were assessed by GC-MS, by comparison with corresponding authentic samples. A typical monomer distribution is illustrated in Fig. 2a (Additional file 1: Table S2). Increased total phenolic monomer yields were observed with the rise of reaction temperature in a range of $200-240{ }^{\circ} \mathrm{C}$, thus reaching maximum yield of $49.8 \mathrm{wt} \%$. Commonly, the maximum theoretical yield of monomers will be approximately equal to the square of the fraction of cleavable $\beta-O-4$ structures in the lignin polymer structure [48]. In view of ca. $70 \% \beta$-O-4 linkages have been quantified in Eucalyptus protolignin [49], the here obtained monomers yield has reached the theoretic maximum value. In the monomers, 4-propanol guaiacol (12.9 wt\%) and 4-propanol syringol (31.9 wt\%) were identified as the two major phenolic products with $90 \%$ selectivity, being consistent with previous report [38]. A proposed pathway to the major products included the cleavage of $\mathrm{C}-\mathrm{O}$ bonds in $\beta-O-4$ linkages leading to monolignols and subsequent reduction of $\mathrm{C}=\mathrm{C}$ bonds, and both steps would be catalyzed by $\mathrm{Pd} / \mathrm{C}$. The RCF reaction at $200{ }^{\circ} \mathrm{C}$ for $8 \mathrm{~h}$ and $250{ }^{\circ} \mathrm{C}$ for $2 \mathrm{~h}$ with $\mathrm{Pd} / \mathrm{C}$ catalyst was also performed (Additional file 1: Table S3, entries 5-6), which afforded phenolic monomer yields in 36.6 and $30.9 \mathrm{wt} \%$, respectively. Several solvents were screened in the RCF of Eucalyptus sawdust in presence of $\mathrm{Pd} / \mathrm{C}$ under $240{ }^{\circ} \mathrm{C}, 4 \mathrm{~h}$ and $\mathrm{H}_{2}$ atmosphere (Additional file 1: Table S3, entries 1-4). Ethanol, isopropanol and water gave $42.4,40.0$ and $35.0 \mathrm{wt} \%$ yields of monomeric phenols, which were lower than that in $\mathrm{MeOH}$ (49.8 wt\%). The high polarity of methanol is conducive to the extraction of lignin due to its permeation into the lignocellulosic matrix and the conversion of lignin oligomers to phenolic monomers. Finally, temperature for $240{ }^{\circ} \mathrm{C}$ and time for $4 \mathrm{~h}$ in $\mathrm{MeOH}$ were chosen as the optimized condition for RCF reaction of Eucalyptus. Gel permeation chromatography (GPC) analysis exhibited a significant decrease in molecular weight $\left(M_{\mathrm{w}}=470\right.$ $430 \mathrm{~g} \mathrm{~mol}^{-1}$ ) relative to the isolated milled wood lignin (MWL, $5630 \mathrm{~g} / \mathrm{mol}$ ) [50] and enzymatic mild acidolysis lignin (EMAL, $8100 \mathrm{~g} \mathrm{~mol}^{-1}$ ) from Eucalyptus tree [34].

A 2D HSQC NMR spectra of the lignin oil was collected (Fig. 3). The main substructures, such as $\beta$-aryl ether $(\beta-O-4, A)$, resinol $(\beta-\beta, B)$, phenyl coumaran $(\beta-5, C)$, have disappeared after $\mathrm{Pd} / \mathrm{C}$ treatment, indicating a nearly thorough $\mathrm{C}-\mathrm{O}$ bonds dissociation in the protolignin. Newly, dominant cross peaks which correspond to a propanol moiety $(31.7 / 2.49,34.5 / 1.68$ and $60.1 / 3.40 \mathrm{ppm}$, labeled in atrovirens) were observed in HSQC, in line with the observation of GC-MS analysis. The cross signals at aromatic region corresponding to guaiacyl $(G)$ and syringyl $(S)$ were also found at 112.2/6.71 $\left(\mathrm{G}_{2}\right), 115.0 / 6.64\left(\mathrm{G}_{5}\right), 120.0 / 6.55\left(\mathrm{G}_{6}\right)$ and $105.4 / 6.41 \mathrm{ppm}\left(\mathrm{S}_{2,6}\right)$, respectively.

The carbohydrate and the catalyst were left in the insoluble fraction after RCF treatment, which could be separated from the reaction mixture through filtration. Screening of the solid residue with a 300-mesh sieve can recover $91 \%$ of $\mathrm{Pd} / \mathrm{C}$, which was then subjected to simple washing and was used directly in the following cycle. As shown in Fig. 4, the yields of phenolic monomers were still retained at $35.1 \mathrm{wt} \%$ in the fourth run, with high selectivity towards 4-propanol guaiacol and 4-propanol syringol. These results indicated a good recycling stability of the $\mathrm{Pd} / \mathrm{C}$ catalyst, which is important for the potential applications in industry.

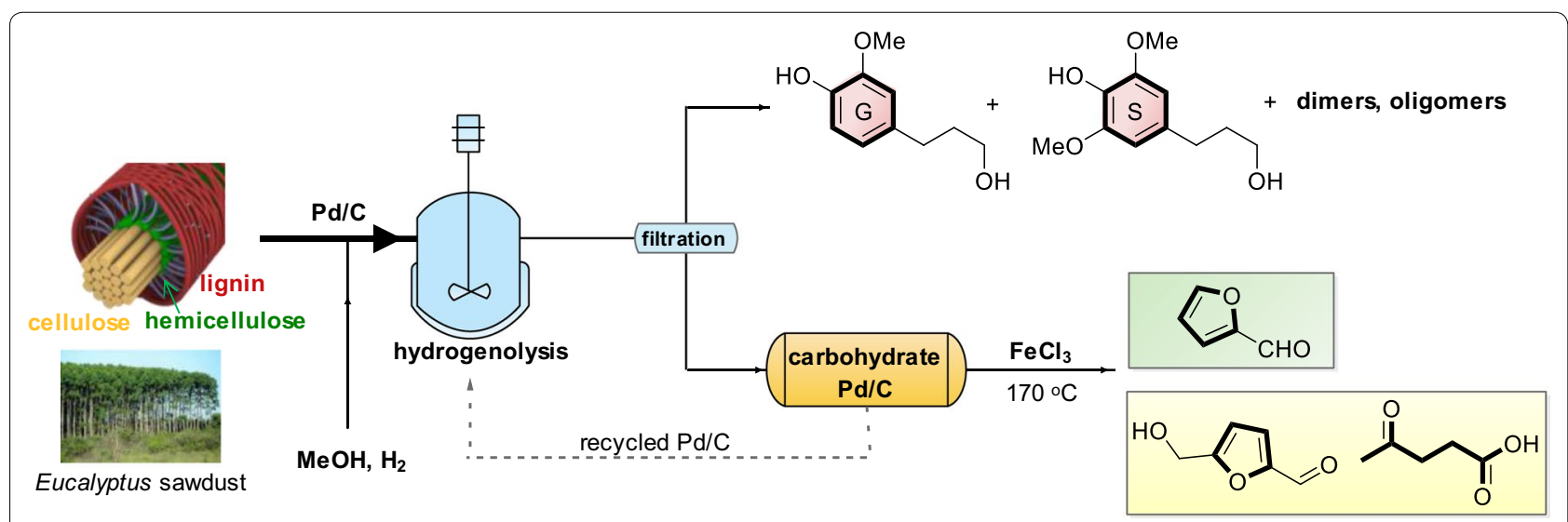

Fig. 1 Schematic representation of the reductive catalytic fractionation (RCF) of Eucalyptus 
Table 1 Comparison of the results after the RCF of Eucalyptus under different temperatures

\begin{tabular}{|c|c|c|c|c|c|c|c|c|}
\hline \multirow[t]{2}{*}{ Entry } & \multirow[t]{2}{*}{ Temp. $\left({ }^{\circ} \mathrm{C}\right)$} & \multirow[t]{2}{*}{$M_{\mathrm{W}}\left(\mathrm{g} \mathrm{mol}^{-1}\right)$} & \multicolumn{4}{|c|}{ Phenolic monomers yield (wt $\%)^{a}$} & \multicolumn{2}{|c|}{$\begin{array}{l}\text { Sugar retention } \\
(w t \%)^{b}\end{array}$} \\
\hline & & & & & Others & Total & $\mathrm{C} 6$ & C5 \\
\hline 1 & 200 & 470 & 7.3 & 18.0 & 1.1 & 26.4 & 81.7 & 87.9 \\
\hline 2 & 220 & 460 & 8.2 & 19.8 & 2.6 & 30.6 & 82.6 & 82.9 \\
\hline 3 & 230 & 460 & 10.8 & 26.8 & 4.1 & 41.7 & 81.5 & 72.3 \\
\hline 4 & 240 & 450 & 12.9 & 31.9 & 5.0 & 49.8 & 82.5 & 67.8 \\
\hline 5 & 250 & 430 & 11.8 & 28.8 & 4.1 & 44.7 & 68.8 & 57.2 \\
\hline
\end{tabular}

Reaction conditions: Eucalyptus (1.0 g), $10 \mathrm{wt} \% \mathrm{Pd} / \mathrm{C}$ catalyst (100 mg), MeOH (40 mL), $\mathrm{H}_{2}(30 \mathrm{~atm}), 4 \mathrm{~h}$

a Based on total lignin content in Eucalyptus

${ }^{b}$ Based on the chemical composition of insoluble fractions

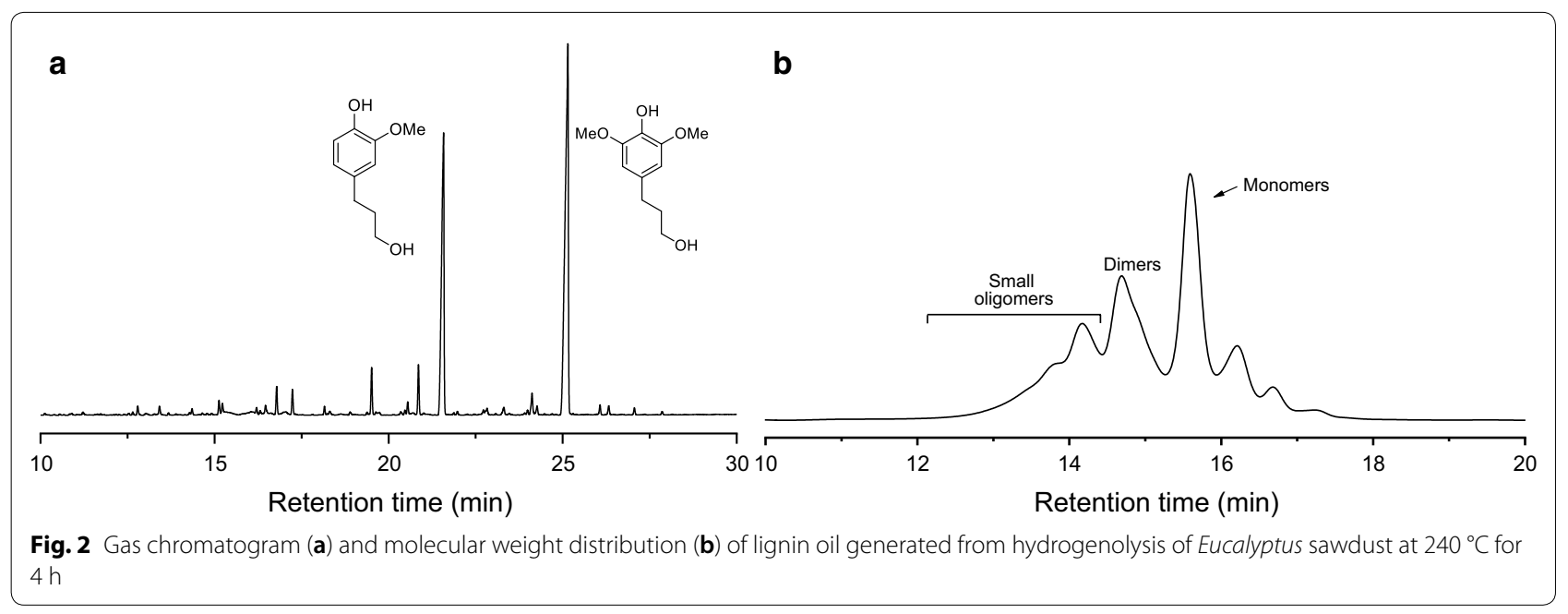

\section{Conversion of the solid carbohydrate residue to 5-HMF, LA and furfural}

The chemical composition of leftover carbohydrate pulp, obtained at the maximum phenolic monomers concurrently, was analyzed by NREL procedure. The retentions of cellulose and hemicellulose in carbohydrate pulp were determined as $82.5 \mathrm{wt} \%$ and $67.8 \mathrm{wt} \%$, respectively. XRD-analysis (Additional file 1: Fig. S4) showed that the crystallinity of the carbohydrate pulp (60.2\%) was much higher than that of the Eucalyptus sawdust (36.2\%), mainly due to the removal of lignin component from biomass matrix and the degradation of amorphous cellulose under current reaction condition. The degree of delignification was also determined as $80.6 \%$, suggesting that the lignin carbohydrate complexes have been destroyed and the solid carbohydrate pulp is suitable candidate for the co-production of platform chemicals.

In an acidic reaction condition, the transformation of hemicellulose into furfural is much sooner than the generation of 5-HMF and levulinic acid from cellulose [51]. Of note, the competing side reactions of (hemi)cellulose leading to unwanted humins are also involved in acid-catalysis systems. To find the proper balance among the efficiency and selectivity of these two biopolymers conversion, as well as avoiding the condensation, is important in maximizing the co-production of platform chemicals in an integrated process. Initially, the conversion of carbohydrate pulp was performed in a biphasic solvent system composed by 2-methyl tetrahydrofuran (MeTHF) and saturated $\mathrm{NaCl}$ aqueous solution with a volume ratio of 3:1. A series of metal chloride catalysts, such as $\mathrm{FeCl}_{3}, \mathrm{AlCl}_{3}$, $\mathrm{CuCl}_{2} \cdot 2 \mathrm{H}_{2} \mathrm{O}, \mathrm{CrCl}_{3}$ and $\mathrm{ZrCl}_{4}$, were screened at $170{ }^{\circ} \mathrm{C}$ for $120 \mathrm{~min}$ (Fig. 5a). High conversions of cellulose were observed, from which 5-HMF and levulinic acid were both generated in high combined yields (48.3$78.4 \%)$. Obviously, levulinic acid was the primary product, probably because 5-HMF is readily hydrolyzed into 


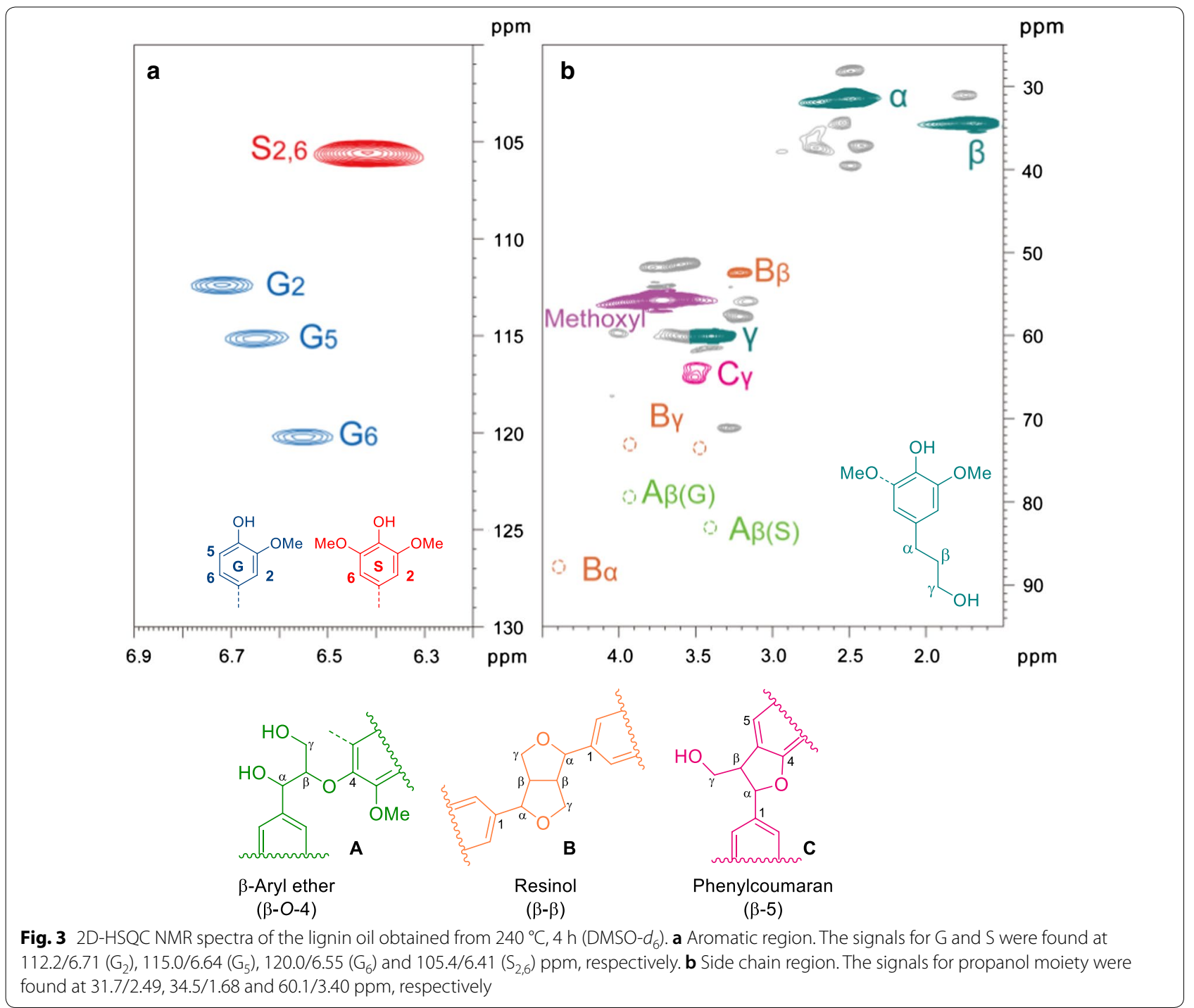

levulinic acid and formic acid under current acidic conditions [52]. This scenario was in line with the observations of acid-treated biomass sawdust [53]. For the case of hemicellulose, $\mathrm{FeCl}_{3}$ was superior to other metal chlorides, which gave furfural in $59.9 \%$ yield. A strong acid, $\mathrm{H}_{2} \mathrm{SO}_{4}$ was also utilized to treat the carbohydrate pulp, which outperformed in the conversion of hemicellulose fraction into furfural (45.7\%). In consideration of total products from carbohydrate pulp, $\mathrm{FeCl}_{3}$ was chosen as the best catalyst for the further investigation.

Reaction medium is a critical factor determining the reaction environment in the transformation of biomass feedstocks to platform chemicals [54]. To study the role of the solvent, some organic solvents combined with saturated $\mathrm{NaCl}$ aqueous solution in 3:1 ratio were tested in the presence of $\mathrm{FeCl}_{3}$ at $170{ }^{\circ} \mathrm{C}$ for $120 \mathrm{~min}$ (Fig. 5b). Apart from dimethyl sulfoxide (DMSO), furfural could be generated from hemicellulose in a desirable fashion in different biphasic systems (43.9-59.9\%). Significant influence on cellulose conversion was observed with the variation of organic solvent partner. Apparently, DMSO or toluene is not a proper organic integrant, in which poor detectable products derived from cellulose were generated. When THF or GVL was combined with $\mathrm{NaCl}$ aqueous solution, only 5-HMF was formed, with no observation of levulinic acid. This scenario is consistent with the observation from reaction of cellulose $[55,56]$ and biomass sawdust $[46,57]$. On the contrary, 


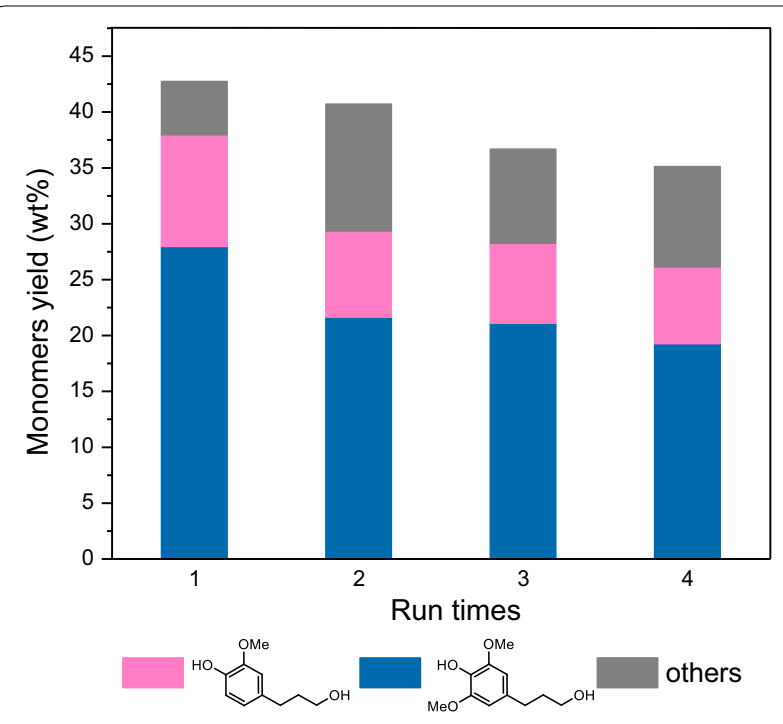

Fig. 4 Results of recycling the Pd/C for Eucalyptus sawdust

levulinic acid (31.4\%) was detected exclusively when dichloromethane (DCM) was partnered. In the case of MeTHF and methylisobutylketone (MIBK), levulinic acid was generated as the main product in $47.6 \%$ and $26.1 \%$ yields, respectively, together with the observation of 5-HMF. Thereby, the ingredient of organic solvent in biphasic systems can modulate the reactivity and selectivity of carbohydrate transformation. The influence of volume ratio of MeTHF and saturated $\mathrm{NaCl}$ aqueous solution was also investigated, as shown in Fig. 5c. Varying the MeTHF-water ratio from 3:1 to 1:3 led to the decrease of furfural (29.1\%), 5-HMF (3.0\%) and levulinic acid (22.5\%) synchronously. A sole solvent, such as MeTHF or saturated $\mathrm{NaCl}$ aqueous solution was used, in which reduced yields of 5-HMF and levulinic acid were observed. Obviously, biphasic solvent plays an imperative role in promoting the conversion of cellulose by the partitioning of resulted 5-HMF and levulinic acid into organic MeTHF phase [58]. Finally, the biphasic system composed with MeTHF and saturated $\mathrm{NaCl}$ aqueous solution in 3:1 ratio proved to be the best choice for the co-conversion of cellulose and hemicellulose.

To assess the influence of reaction time and temperature on the co-production platform compounds, reaction time-course data at different temperatures were obtained and shown in Fig. 6. Either raising reaction temperature or prolonging reaction time enhanced the production of levulinic acid, because harsh condition is favorable to the depolymerization of the crystalline cellulose and subsequent hydrolysis reaction. The temperatures of $170{ }^{\circ} \mathrm{C}$ and $180{ }^{\circ} \mathrm{C}$ were not sufficient to form levulinic acid entirely, and maximal yield (74.6\%) of levulinic acid was achieved at $200{ }^{\circ} \mathrm{C}, 100 \mathrm{~min}$ or $190{ }^{\circ} \mathrm{C}, 120 \mathrm{~min}$. Under such a case, no 5-HMF was observed, suggesting a complete conversion from 5-HMF to levulinic acid. Further prolonging reaction time at $190{ }^{\circ} \mathrm{C}$ or $200{ }^{\circ} \mathrm{C}$ resulted in the decrease of levulinic acid, probably because of the formation of humin.

For the case of conversion of hemicellulose, the formation of furfural was increasing smoothly with the reaction time at a relative low temperature (such as $170{ }^{\circ} \mathrm{C}$ ), and the yield reached to $60.8 \%$ in 140 min finally. This confirmed that the conversion of hemicellulose occurred more readily than cellulose. At higher temperatures $\left(180{ }^{\circ} \mathrm{C}, 190{ }^{\circ} \mathrm{C}\right.$ and $\left.200{ }^{\circ} \mathrm{C}\right)$, the maximum yield of furfural (ca. $60 \%$ ) could be realized rapidly; however, dramatic decline of furfural was also observed with prolonging the reaction time, because high temperatures not only facilitated the dehydration of xylose, but also accelerated the degradation of furfural [59]. Based on the above experiment results, the optimal reaction condition for the co-conversion hemicellulose and cellulose was established as $190{ }^{\circ} \mathrm{C}$ and $100 \mathrm{~min}$, from which furfural and levulinic acid were obtained in $55.9 \%$ and $73.6 \%$ yield, respectively.
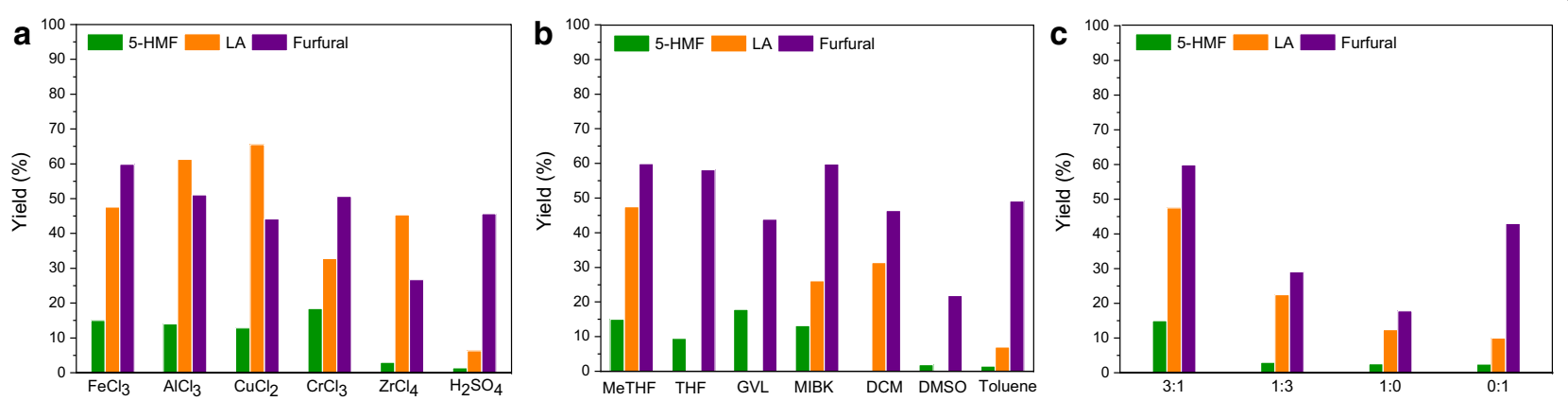

Fig. 5 Conversion of solid carbohydrate residue to platform chemicals. a Catalysts screening in MeTHF/saturated NaCl (3:1) aqueous solution; b different organic solvent with saturated $\mathrm{NaCl}$ aqueous solution in 3:1 ratio; c ratios screening of MeTHF and saturated $\mathrm{NaCl}$ aqueous solution. General conditions: carbohydrate pulp $(0.15 \mathrm{~g})$, metal halide catalysts in biphasic solvent $(0.1 \mathrm{M}, 12 \mathrm{~mL}), 170{ }^{\circ} \mathrm{C}$ for $120 \mathrm{~min}$ 
A mass balance of the RCF combined with $\mathrm{FeCl}_{3}$ catalysis A process mass balance of the combination of RCF with $\mathrm{FeCl}_{3}$ catalysis was described based on $1.0 \mathrm{~g}$ of dried Eucalyptus (Fig. 7). Under optimized conditions, lignin component (ca. $269 \mathrm{mg}$ ) in biomass matrix can be depolymerized into monomers $(134 \mathrm{mg})$, dimers and oligomers through RCF process, which could be solubilized in methanol. Under such a condition, the leftover solid residue, contained cellulose (343 $\mathrm{mg}$ ), hemicellulose $(133 \mathrm{mg})$ and $\mathrm{Pd} / \mathrm{C}$ catalyst. Upon the treatment of $\mathrm{FeCl}_{3}$, the leftover carbohydrate pulp yielded furfural $(74 \mathrm{mg}$ ) and levulinic acid (252 mg) in an integrated version. Partial xylan presented in methanol, could also be recovered and transferred into furfural $(14 \mathrm{mg})$. The resulted products, i.e., levulinic acid, furfural and monophenols, corresponded to $61 \%$ of cellulose, $45 \%$ of hemicellulose and $50 \%$ of lignin, respectively. Ultimately, $54 \%$ of Eucalyptus sawdust can be converted into well-defined chemicals under such an integrated biorefinery method.

\section{Conclusions}

RCF followed by $\mathrm{FeCl}_{3}$ catalysis was employed for the fractionation of all three components in Eucalyptus. Results showed that high monomers yield of $49.8 \mathrm{wt} \%$ close to the theoretical maximum was obtained during RCF process, next to high retentions of cellulose and hemicellulose components. Then, $\mathrm{FeCl}_{3}$ was used to convert the cellulose and hemicellulose in carbohydrate pulp to 5-HMF, LA and furfural simultaneously. The furfural and LA yields reached $55.9 \%$ and $73.6 \%$, respectively, when the reaction condition was established as $190{ }^{\circ} \mathrm{C}$ and $100 \mathrm{~min}$. This study provides an efficient method for fractionation and sequential utilization of all three major components in Eucalyptus.

\section{Materials and methods}

\section{Material}

Eucalyptus sawdust was harvested from Guangxi Province. The Eucalyptus sawdust was mainly composed of 41.6\% cellulose, $19.6 \%$ hemicellulose, $27.0 \%$ lignin, $3.2 \%$ extract, and $0.2 \%$ ash. The dried Eucalyptus was grounded in a mill to obtain a 40-60 mesh fraction, which was further extracted with toluene/ethanol $(2: 1, \mathrm{v} / \mathrm{v})$ and dried for further experiment. $\mathrm{Pd} / \mathrm{C}$ catalyst (where $\mathrm{Pd}$ content is $5 \mathrm{wt} \%$ ) was purchased from Energy Chemical. The metal halide catalysts $\left(\mathrm{FeCl}_{3}, \mathrm{AlCl}_{3}, \mathrm{CuCl}_{2} \cdot 2 \mathrm{H}_{2} \mathrm{O}, \mathrm{CrCl}_{3}\right.$, and $\mathrm{ZrCl}_{4}$ ) were used and loaded based on their equivalent anhydrous mass to achieve $0.10 \mathrm{M}$ catalyst loading.

\section{General catalytic reaction}

RCF experiments were performed in a $100-\mathrm{mL}$ stainless steel batch reactor (Parr instruments Co.) equipped with a 60-mL glass tube. In a typical reaction, extracted Eucalyptus sawdust $(1.0 \mathrm{~g}), \mathrm{Pd} / \mathrm{C}(100 \mathrm{mg}, 10 \mathrm{wt} \%)$ and methanol $(40 \mathrm{~mL})$ were charged into the reactor, which was then sealed, flushed with $\mathrm{N}_{2}$ and pressurized with $\mathrm{H}_{2}$ at room temperature. The reaction mixture was heated at desired temperature with magnetic stirring $(800 \mathrm{rpm})$. After reaction, the reactor was cooled immediately by ice water. The mixture was filtered with Buchner funnel, thus giving soluble fraction containing phenolic compounds and insoluble fractions containing carbohydrate pulp and $\mathrm{Pd} / \mathrm{C}$.

\section{Lignin products analysis}

The soluble fraction was concentrated by a rotary evaporation to remove methanol and extracted with dichloromethane and water. Subsequent removal of dichloromethane of the organic phase gave a brown "lignin oil". The lignin oil with a standard (tetradecane) was dissolved
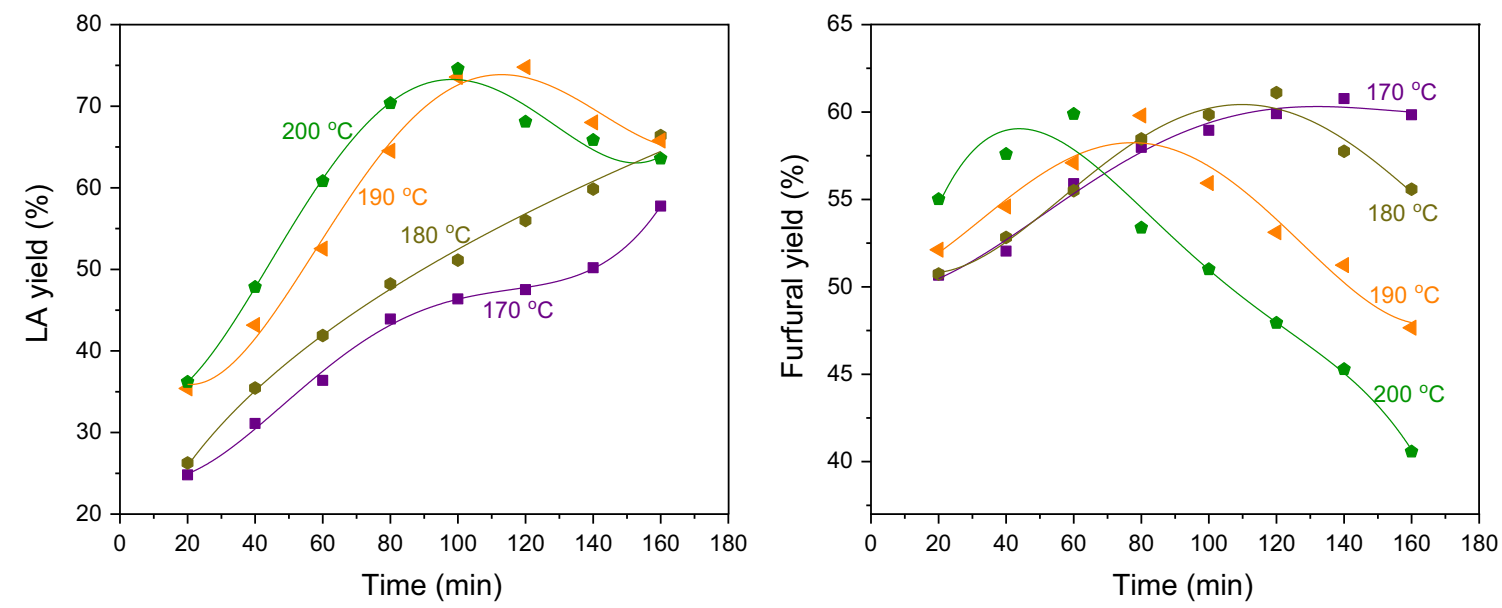

Fig. 6 Effect of reaction temperature and time on solid carbohydrate residue conversion to furfural and LA. Reaction conditions: carbohydrate pulp $(0.15 \mathrm{~g}), \mathrm{FeCl}_{3}$ in $\mathrm{MeTHF} /$ saturated $\mathrm{NaCl}$ aqueous solution $(0.1 \mathrm{M}, 12 \mathrm{~mL})$ 


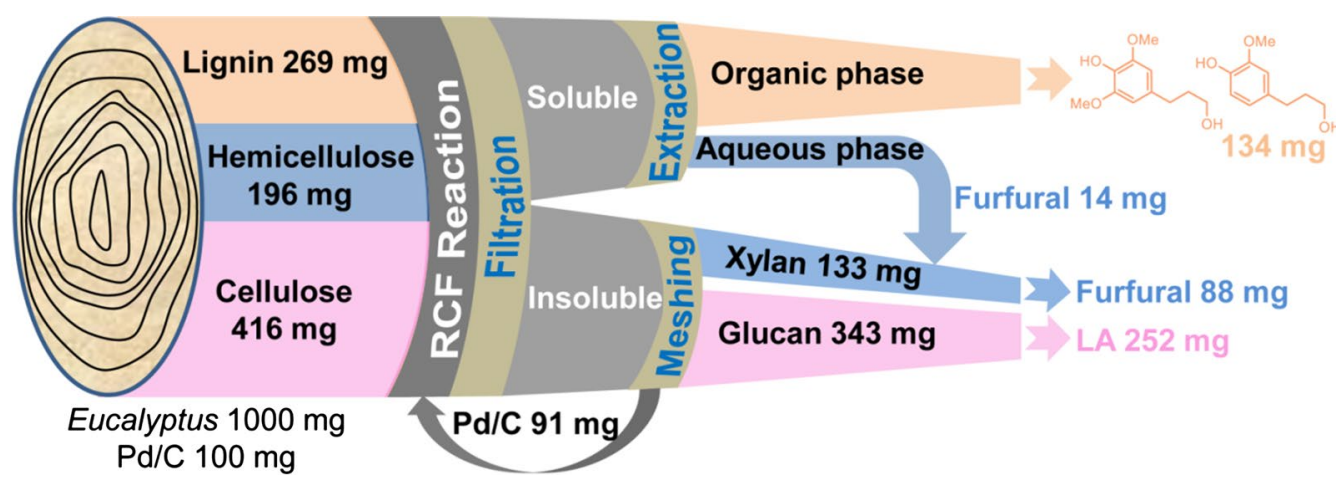

Fig. 7 Mass balance calculation of the reductive catalytic fractionation (RCF) combined with $\mathrm{FeCl}_{3}$ catalysis

in dichloromethane in a 10-mL volumetric flask for determination, which was analyed by gas chromatography coupled with mass spectrometer (GC-MS) and gas chromatography $(\mathrm{GC})$ to identify and quantify the monomeric phenols as described in Additional file 1. The phenolic monomers yield and sugar retention were calculated from equations:

Phenolic monomers yield (wt\%)

$$
=\frac{m(\text { total phenolic monomers })}{m(\text { total lignin })} \times 100 \% \text {, }
$$

$$
\begin{aligned}
& \text { C6 sugar retention }(\mathrm{wt} \%) \\
& =\frac{m(\text { cellulose in insoluble fraction })}{m(\text { total cellulose })} \times 100 \%
\end{aligned}
$$

$$
\begin{aligned}
& \text { C5 sugar retention (wt } \%) \\
& =\frac{m(\text { hemicellulose in insoluble fraction })}{m \text { (total hemicellulose) }} \times 100 \% .
\end{aligned}
$$

The molecular weight of the lignin oil was determined by gel permeation chromatography (GPC) equipped with a UV detector $(254 \mathrm{~nm}$ ) and PL-gel mixed-B column (10 $\mathrm{mm} \times 7.5 \mathrm{~mm}$ i.d.), where THF was as the solvent $(0.5 \mathrm{~mL} / \mathrm{min})$. A THF solution of lignin oil $(2 \mathrm{mg} / \mathrm{mL})$ was used for injection. Two-dimensional heteronuclear single quantum coherence (2D HSQC) NMR analysis was acquired on a Bruker Avance $400 \mathrm{MHz}$ spectrometer using DMSO- $d_{6}(0.5 \mathrm{~mL})$ as a solvent [60].

\section{Compositional analysis of carbohydrate pulp}

The $\mathrm{Pd} / \mathrm{C}$ catalyst in the insoluble fraction could be separated and recycled in $91 \%$ yield through a mesh screening (300 mesh). The remaining carbohydrate pulp was then subjected to chemical composition analysis by sulfuric acid hydrolysis according to the National Renewable Energy Laboratory
(NREL) procedure [61]. The chemical composition of the Eucalyptus sawdust was also determined by NREL procedure.

\section{Conversion of the carbohydrate pulp into LA and furfural}

Typically, the experiments were carried out in a $15-\mathrm{mL}$ sealed tube with carbohydrate pulp $(150 \mathrm{mg})$, catalyst $(0.10 \mathrm{M})$ and solvent $(12 \mathrm{~mL})$ under magnetic stirring. The tube in stainless steel reactor was heated to a given temperature $\left(170,180,190\right.$, and $\left.200{ }^{\circ} \mathrm{C}\right)$ and maintained for different times (20,40,60, 80, 100, 120, 140, and $160 \mathrm{~min}$ ). After the reaction, the reactant was cooled to room temperature and extracted with dichloromethane and water, and the organic phase was subjected to high-performance liquid chromatography (HPLC) analysis. The detailed analytical method is presented in Additional file 1. LA and FF yields were calculated based on following equations:

LA yield (\%)

$=\frac{\text { moles of LA produced }}{\text { moles of staring glucan in carbohydrate pulp }} \times 100 \%$,

FF yield (\%)

$=\frac{\text { moles of FF produced }}{\text { moles of staring xylan in carbohydrate pulp }} \times 100 \%$.

\section{Supplementary information}

Supplementary information accompanies this paper at https://doi. org/10.1186/s13068-019-1644-z.

Additional file 1: Table S1. The chemical composition of Eucalyptus sawdust and carbohydrate pulp. Table S2. Reductive catalytic fractionation of Eucalyptus under different temperature. Table S3. Reductive catalytic fractionation of Eucalyptus under different temperature, time, and solvent. Fig. S1. Schematic representation of Pd/C-catalyzed RCF of Eucalyptus sawdust. Fig. S2. Gas chromatograms and peak identification of the lignin monomers from catalytic hydrogenolysis of Eucalyptus sawdust using Pd/C catalyst. Fig. S3. 'H NMR spectra of 4-propanol syringol. Fig. S4. ${ }^{13} \mathrm{C}$ NMR spectra of 4-propanol syringol. Fig. S5. ${ }^{1} \mathrm{H}$ NMR spectra of 4-propanol guaiacol. Fig. S6. ${ }^{13} \mathrm{C}$ NMR spectra of 4-propanol guaiacol. Fig. S7. The X-ray diffraction patterns of Eucalyptus sawdust and solid residue obtained from the RCF. 


\begin{abstract}
Abbreviations
5-HMF: 5-hydroxymethylfurfural; LA: levulinic acid; RCF: reductive catalytic fractionation; GVL: Y-valerolactone; Mw: molecular weight; GPC: gel permeation chromatography; MWL: milled wood lignin; EMAL: enzymatic mild acidolysis lignin; MeTHF: 2-methyl tetrahydrofuran; DCM: dichloromethane; MIBK: methylisobutylketone; DMSO: dimethyl sulfoxide.
\end{abstract}

\section{Acknowledgements}

Not applicable.

\section{Authors' contributions}

GYS, LPX, and XC conceived the project; LPX and XC designed the experiments; $X C$ and KLZ performed the experiments; GYS, XC, and RCS analyzed the data; GYS and XC wrote the paper. All authors read and approved the final manuscript.

\section{Funding}

This work was supported by the National Natural Science Foundation of China (No. 21776020), the Natural Science Foundation of Liaoning Province (No. 2019-MS-019), and the Science Foundation of Dalian Polytechnic University (No. 61010201).

\section{Availability of data and materials}

All data generated or analyzed during this study are included in this published article and its supplementary information files.

\section{Ethics approval and consent to participate}

Not applicable.

\section{Consent for publication}

Not applicable.

\section{Competing interests}

The authors declare that they have no competing interests.

Received: 4 November 2019 Accepted: 22 December 2019

Published online: 06 January 2020

\section{References}

1. Zhao X, Zhou H, Sikarwar VS, Zhao M, Park AHA, Fennell PS, Shen L, Fan LS. Biomass-based chemical looping technologies: the good, the bad and the future. Energy Environ Sci. 2017;10:1885-910.

2. Tuck CO, Pérez E, Horváth IT, Sheldon RA, Poliakoff M. Valorization of biomass: deriving more value from waste. Science. 2012:337:695-9.

3. Sathitsuksanoh N, Holtman KM, Yelle DJ, Morgan T, Stavila V, Pelton J, Blanch $\mathrm{H}$, Simmons BA, George A. Lignin fate and characterization during ionic liquid biomass pretreatment for renewable chemicals and fuels production. Green Chem. 2014;16:1236-47.

4. Kamm B, Gruber PR, Kamm M. Biorefineries-industrial processes and products. Weinheim: Wiley; 2006.

5. Wyman CE. Aqueous pretreatment of plant biomass for biological and chemical conversion to fuels and chemicals. Hoboken: Wiley; 2013.

6. Liu S. Woody biomass: niche position as a source of sustainable renewable chemicals and energy and kinetics of hot-water extraction/hydrolysis. Biotechnol Adv. 2010;28:563-82.

7. Upton BM, Kasko AM. Strategies for the conversion of lignin to high-value polymeric materials: review and perspective. Chem Rev. 2015;116:2275-306

8. Rinaldi R, Jastrzebski R, Clough MT, Ralph J, Kennema M, Bruijnincx PC, Weckhuysen BM. Paving the way for lignin valorisation: recent advances in bioengineering, biorefining and catalysis. Angew Chem Int Ed. 2016;55:8164-215.

9. Arun A, Eyini M. Comparative studies on lignin and polycyclic aromatic hydrocarbons degradation by basidiomycetes fungi. Bioresource Technol. 2011;102:8063-70.

10. Cai CM, Zhang T, Kumar R, Wyman CE. THF co-solvent enhances hydrocarbon fuel precursor yields from lignocellulosic biomass. Green Chem. 2013;15:3140-5.
11. Alonso DM, Wettstein SG, Mellmer MA, Gurbuz El, Dumesic JA. Integrated conversion of hemicellulose and cellulose from lignocellulosic biomass. Energy Environ Sci. 2013;6:76-80.

12. Pileidis FD, Titirici MM. Levulinic acid biorefineries: new challenges for efficient utilization of biomass. Chemsuschem. 2016;9:562-82.

13. Hu L, Zhao G, Hao W, Tang X, Sun Y, Lin L, Liu S. Catalytic conversion of biomass-derived carbohydrates into fuels and chemicals via furanic aldehydes. Rsc Adv. 2012;2:11184-206.

14. Li Z, Qiu C, Gao J, Wang H, Qin M. Improving lignin removal from prehydrolysis liquor by horseradish peroxidase-catalyzed polymerization. Sep Purif Technol. 2019;212:273-9.

15. Renders T, Van den Bosch S, Koelewijn S-F, Schutyser W, Sels B. Lignin-first biomass fractionation: the advent of active stabilisation strategies. Energy Environ Sci. 2017:10:1551-7.

16. Constant S, Wienk HL, Frissen AE, de Peinder P, Boelens R, Van Es DS, Grise RJ, Weckhuysen BM, Huijgen WJ, Gosselink RJ. New insights into the structure and composition of technical lignins: a comparative characterisation study. Green Chem. 2016;18:2651-65.

17. Monsigny L, Feghali E, Berthet J-C, Cantat T. Efficient reductive depolymerization of hardwood and softwood lignins with Brookhart's iridium (iii) catalyst and hydrosilanes. Green Chem. 2018;20:1981-6.

18. Guo H, Miles-Barrett DM, Zhang B, Wang A, Zhang T, Westwood NJ, Li C. Is oxidation-reduction a real robust strategy for lignin conversion? A comparative study on lignin and model compounds. Green Chem. 2019:21:803-11.

19. Schutyser W, Renders T, Van den Bosch S, Koelewijn S-F, Beckham G, Sels BF. Chemicals from lignin: an interplay of lignocellulose fractionation, depolymerisation, and upgrading. Chem Soc Rev. 2018;47:852-908.

20. Van den Bosch S, Schutyser W, Vanholme R, Driessen T, Koelewijn S-F, Renders T, De Meester B, Huijgen W, Dehaen W, Courtin C. Reductive lignocellulose fractionation into soluble lignin-derived phenolic monomers and dimers and processable carbohydrate pulps. Energy Environ Sci. 2015;8:1748-63.

21. Li H, Song G. Ru-catalyzed hydrogenolysis of lignin: base-dependent tunability of monomeric phenols and mechanistic study. ACS Catal. 2019:5:4054-64.

22. Klein I, Marcum C, Kenttämaa H, Abu-Omar MM. Mechanistic investigation of the $\mathrm{Zn} / \mathrm{Pd} / \mathrm{C}$ catalyzed cleavage and hydrodeoxygenation of lignin. Green Chem. 2016;18:2399-405.

23. Zhang K, Li H, Xiao L-P, Wang B, Sun R-C, Song G. Sequential utilization of bamboo biomass through reductive catalytic fractionation of lignin. Biores Technol. 2019:285:121335.

24. Gao F, Webb JD, Sorek H, Wemmer DE, Hartwig JF. Fragmentation of lignin samples with commercial $\mathrm{Pd} / \mathrm{C}$ under ambient pressure of hydrogen. ACS Catal. 2016;6:7385-92.

25. Galkin MV, Sawadjoon S, Rohde V, Dawange M, Samec JS. Mild heterogeneous palladium-catalyzed cleavage of $\beta$-O- $4^{\prime}$-ether linkages of lignin model compounds and native lignin in air. ChemCatChem. 2014;6:179-84

26. Schutyser W, Van den Bosch S, Renders T, De Boe T, Koelewijn S-F, Dewaele A, Ennaert T, Verkinderen O, Goderis B, Courtin C. Influence of bio-based solvents on the catalytic reductive fractionation of birch wood. Green Chem. 2015:17:5035-45.

27. Parsell TH, Owen BC, Klein I, Jarrell TM, Marcum CL, Haupert LJ, Amundson LM, Kenttämaa HI, Ribeiro F, Miller JT. Cleavage and hydrodeoxygenation (HDO) of $\mathrm{C}-\mathrm{O}$ bonds relevant to lignin conversion using $\mathrm{Pd} / \mathrm{Zn}$ synergistic catalysis. Chem Sci. 2013;4:806-13.

28. Li Y, Demir B, Ramos LMV, Chen M, Dumesic JA, Ralph J. Kinetic and mechanistic insights into hydrogenolysis of lignin to monomers in a continuous flow reactor. Green Chem. 2019:21:3561.

29. Song Q, Wang F, Cai J, Wang Y, Zhang J, Yu W, Xu J. Lignin depolymerization (LDP) in alcohol over nickel-based catalysts via a fragmentationhydrogenolysis process. Energy Environ Sci. 2013;6:994-1007.

30. Wang S, Gao W, Xiao L-P, Shi J, Sun R-C, Song G. Hydrogenolysis of biorefinery corncob lignin into aromatic phenols over activated carbonsupported nickel. Sustain Energy Fuels. 2019:3:401-8.

31. Liu X, Li H, Xiao L-P, Sun R-C, Song G. Chemodivergent hydrogenolysis of eucalyptus lignin with Ni@ ZIF-8 catalyst. Green Chem. 2019;21:1498-504. 
32. Sun Z, Bottari G, Afanasenko A, Stuart MC, Deuss PJ, Fridrich B, Barta K. Complete lignocellulose conversion with integrated catalyst recycling yielding valuable aromatics and fuels. Nat Catal. 2018;1:82.

33. Wang S, Gao W, Li H, Xiao LP, Sun RC, Song G. Selective fragmentation of biorefinery corncob lignin into $\mathrm{p}$-hydroxycinnamic esters with a supported zinc molybdate catalyst. Chemsuschem. 2018;11:2114-23.

34. Xiao L-P, Wang S, Li H, Li Z, Shi Z-J, Xiao L, Sun R-C, Fang Y, Song G. Catalytic hydrogenolysis of lignins into phenolic compounds over carbon nanotube supported molybdenum oxide. ACS Catal. 2017;7:7535-42.

35. Sun J, Li H, Xiao L-P, Guo X, Fang Y, Sun R-C, Song G. Fragmentation of woody lignocellulose into primary monolignols and their derivatives. ACS Sustain Chem Eng. 2019;7:4666-74.

36. Parsell T, Yohe S, Degenstein J, Jarrell T, Klein I, Gencer E, Hewetson B, Hurt M, Im Kim J, Choudhari H. A synergistic biorefinery based on catalytic conversion of lignin prior to cellulose starting from lignocellulosic biomass. Green Chem. 2015;17:1492-9.

37. Galkin MV, Samec JS. Selective route to 2-propenyl aryls directly from wood by a tandem organosolv and palladium-catalysed transfer hydrogenolysis. Chemsuschem. 2014;7:2154-8.

38. Van den Bosch S, Schutyser W, Koelewijn S-F, Renders T, Courtin C, Sels B. Tuning the lignin oil $\mathrm{OH}$-content with $\mathrm{Ru}$ and $\mathrm{Pd}$ catalysts during lignin hydrogenolysis on birch wood. Chem Commun. 2015;51:13158-61.

39. Jiang Z, Hu C. Selective extraction and conversion of lignin in actual biomass to monophenols: a review. J Energy Chem. 2016;25:947-56.

40. Anderson EM, Katahira R, Reed M, Resch MG, Karp EM, Beckham GT, Román-Leshkov Y. Reductive catalytic fractionation of corn stover lignin. ACS Sustain Chem Eng. 2016:4:6940-50.

41. Renders T, Van den Bosch S, Vangeel T, Ennaert T, Koelewijn S-F, Van den Bossche G, Courtin CM, Schutyser W, Sels BF. Synergetic effects of alcohol/water mixing on the catalytic reductive fractionation of poplar wood. ACS Sustain Chem Eng. 2016:4:6894-904.

42. Sheldon RA. Green and sustainable manufacture of chemicals from biomass: state of the art. Green Chem. 2014;16:950-63.

43. Wang T, Nolte MW, Shanks BH. Catalytic dehydration of C 6 carbohydrates for the production of hydroxymethylfurfural (HMF) as a versatile platform chemical. Green Chem. 2014;16:548-72.

44. Delidovich I, Leonhard K, Palkovits R. Cellulose and hemicellulose valorisation: an integrated challenge of catalysis and reaction engineering. Energy Environ Sci. 2014;7:2803-30.

45. Nzihou A, Stanmore B, Lyczko N, Minh DP. The catalytic effect of inherent and adsorbed metals on the fast/flash pyrolysis of biomass: a review. Energy. 2019;170:326-37.

46. Cai CM, Nagane N, Kumar R, Wyman CE. Coupling metal halides with a co-solvent to produce furfural and 5-HMF at high yields directly from lignocellulosic biomass as an integrated biofuels strategy. Green Chem. 2014;16:3819-29.

47. Luo H, Klein IM, Jiang Y, Zhu H, Liu B, Kenttämaa HI, Abu-Omar MM. Total utilization of Miscanthus biomass, lignin and carbohydrates, using earth abundant nickel catalyst. ACS Sustain Chem Eng. 2016;4:2316-22.

48. Feghali E, Carrot G, Thuery P, Genre C, Cantat T. Convergent reductive depolymerization of wood lignin to isolated phenol derivatives by metalfree catalytic hydrosilylation. Energy Environ Sci. 2015;8:2734-43.
49. Wen J-L, Sun S-L, Yuan T-Q, Sun R-C. Structural elucidation of whole lignin from Eucalyptus based on preswelling and enzymatic hydrolysis. Green Chem. 2015:17:1589-96.

50. Zhao B-C, Chen B-Y, Yang S, Yuan T-Q, Charlton A, Sun R-C. Structural variation of lignin and lignin-carbohydrate complex in Eucalyptus grandis $\times$ E urophylla during its growth process. ACS Sustain Chem Eng. 2016;5:1113-22.

51. Cai CM, Zhang T, Kumar R, Wyman CE. Integrated furfural production as a renewable fuel and chemical platform from lignocellulosic biomass. J Chem Technol Biotechnol. 2014;89:2-10.

52. Weingarten R, Cho J, Xing R, Conner WC Jr, Huber GW. Kinetics and reaction engineering of levulinic acid production from aqueous glucose solutions. Chemsuschem. 2012:5:1280-90.

53. Szabolcs Á, Molnár M, Dibó G, Mika LT. Microwave-assisted conversion of carbohydrates to levulinic acid: an essential step in biomass conversion. Green Chem. 2013;15:439-45.

54. Peleteiro S, da Costa Lopes AM, Garrote G, Parajó JC, Bogel-Łukasik R. Simple and efficient furfural production from xylose in media containing 1-butyl-3-methylimidazolium hydrogen sulfate. Ind Eng Chem Res. 2015;54:8368-73.

55. Shi N, Liu Q, Zhang Q, Wang T, Ma L. High yield production of 5-hydroxymethylfurfural from cellulose by high concentration of sulfates in biphasic system. Green Chem. 2013;15:1967-74.

56. He J, Liu M, Huang K, Walker TW, Maravelias CT, Dumesic JA, Huber GW. Production of levoglucosenone and 5-hydroxymethylfurfural from cellulose in polar aprotic solvent-water mixtures. Green Chem. 2017;19:3642-53.

57. Xu Z, Li W, Du Z, Wu H, Jameel H, Chang H-M, Ma L. Conversion of corn stalk into furfural using a novel heterogeneous strong acid catalyst in Y-valerolactone. Bioresour Technol. 2015;198:764-71.

58. Román-Leshkov Y, Dumesic JA. Solvent effects on fructose dehydration to 5-hydroxymethylfurfural in biphasic systems saturated with inorganic salts. Top Catal. 2009;52:297-303.

59. Sener C, Motagamwala AH, Alonso DM, Dumesic JA. Enhanced furfural yields from xylose dehydration in the $\gamma$-valerolactone/water solvent system at elevated temperatures. Chemsuschem. 2018;11:2321-31.

60. Xiao L-P, Shi Z-J, Xu F, Sun R-C. Characterization of lignins isolated with alkaline ethanol from the hydrothermal pretreated Tamarix ramosissima. BioEnergy Res. 2013;6:519-32.

61. Sluiter A, Hames B, Ruiz R, Scarlata C, Sluiter J, Templeton D, Crocker D. Determination of structural carbohydrates and lignin in biomass. Lab Anal Proced. 2008:1617:1-16.

\section{Publisher's Note}

Springer Nature remains neutral with regard to jurisdictional claims in published maps and institutional affiliations.

Ready to submit your research? Choose BMC and benefit from

- fast, convenient online submission

- thorough peer review by experienced researchers in your field

- rapid publication on acceptance

- support for research data, including large and complex data types

- gold Open Access which fosters wider collaboration and increased citations

- maximum visibility for your research: over 100M website views per year

At $\mathrm{BMC}$, research is always in progress.

Learn more biomedcentral.com/submissions 